
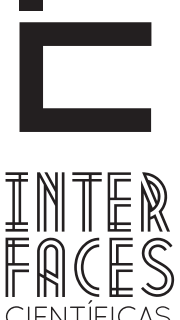

CIENTÍFICAS

HUMANASE SOCIAIS

ISSN IMPRESSO 2316-3348

E-ISSN 2316-3801

DOI - 10.17564/2316-3801.2019v7n3p57-68

\title{
ESPAÇOS NÃO-FORMAIS E A EDUCAÇÃO EM CIÊNCIAS: O PROJETO PRAÇAS DA CIÊNCIA NO ESTADO DA BAHIA
}

NON-FORMAL SPACES AND SCIENCE EDUCATION: MARKETPLACES OF SCIENCE PROJECT IN THE STATE OF BAHIA

ESPACIOS NO FORMALES Y EDUCACIÓN CIENTÍFICA: MERCADOS DE PROYECTO DE CIENCIAS EN EL ESTADO DE BAHÍA

Jean Mário Araujo Costa ${ }^{1}$

Kátia Siqueira de Freitas ${ }^{3}$
Marta Caires de Souza²

\section{RESUMO}

A Educação em Ciências se processa em diversos espaços e contextos. Os espaços não formais tornam-se cada vez mais importantes na Educação Científica na medida em que possibilitam e colaboram para que os conhecimentos científicos e tecnológicos e suas repercussões possam ser acessados por diferentes pessoas e em diferentes perspectivas. Este artigo resultou de revisão bibliográfica e análise documental com o objetivo de discutir as relações entre os espaços não formais e a Educação em Ciências, tendo como foco o projeto Praças da Ciência, implantado no Estado da Bahia-Brasil. Discute-se que o projeto reforça o importante papel das Praças da Ciência como espaços que possibilitam a aproximação da sociedade ao conhecimento científico, bem como com os processos formais de educação, ao mesmo tempo, evidencia a necessidade de maior abrangência do projeto e estratégias didáticas articuladas e regulares no campo do ensino, da divulgação e da popularização da ciência, tendo em vista a relevância que esses espaços desempenham para a Educação em Ciências, seja em âmbito da educação formal ou não.

\section{PALAVRAS-CHAVES}

Espaços Não Formais. Educação em Ciências. Divulgação e Popularização da Ciência. Praças da Ciência. 


\section{ABSTRACT}

The Science Education takes place in different spaces and contexts. Non-formal spaces become increasingly important in Scientific Education insofar as they enable and collaborate so that scientific and technological knowledge and its repercussions can be accessed by different people and in different perspectives. This bibliographical and documentary review article has the objective of discussing the relations between non-formal spaces and Science Education, focusing on the Praças da Ciência implanto project in the State of Bahia-Brazil. It is argued that the project reinforces the important role of the Praça do Ciência as spaces that allow the approximation of society to scientific

\section{RESUMEN}

La Educación en Ciencias se procesa en diversos espacios y contextos. Los espacios no formales se vuelven cada vez más importantes en la Educación Científica en la medida en que posibilitan y colaboran para que los conocimientos científicos y tecnológicos y sus repercusiones puedan ser accedidos por diferentes personas y en diferentes perspectivas. Este artículo resultó de revisión literaria y análisis documental con el objetivo de discutir las relaciones entre los espacios no formales y la Educación en Ciencias, teniendo como foco el proyecto Praças da Ciência, implantado en el Estado de Bahia - Brasil. Se discute que el proyecto refuerza el importante papel de las plazas de ciencia como espacios que posibilitan la aproximación de la sociedad al conoci- knowledge, as well as with the formal processes of education, at the same time, evidences the need for greater comprehensiveness of the project and didactic strategies articulated and regular in the field of teaching, dissemination and popularization of science in articulation, considering the relevance that these spaces play for Science Education, whether in formal education or not.

\section{KEYWORDS}

Non-formal spaces. Education in Sciences. Dissemination and Popularization of Science. Science Square.

miento científico, así como con los procesos formales de educación. Al mismo tiempo, evidencia la necesidad de mayor alcance del proyecto y estrategias didácticas articuladas y frecuentes en los campos de la enseñanza, divulgación y la popularización de la ciencia, teniendo en cuenta la relevancia que estos espacios desempeñan para la Educación en Ciencias, sea en el ámbito de la educación formal o no.

\section{PALABRAS CLAVE}

Espacios no formales. Educación en Ciencias. Divulgación y Popularización de la Ciencia. Plaza de la Ciencia. 


\section{INTRODUÇ̃̃O}

A história do Brasil tem revelado a preponderância de desigualdades sociais no tocante à distribuição da riqueza, da terra, do acesso aos bens materiais e culturais e especialmente da apropriação dos conhecimentos científicos e tecnológicos. Assim, um dos grandes desafios do país reside na necessidade premente de democratização do acesso aos conhecimentos científicos e tecnológicos, no sentido de propiciar aos cidadãos uma melhor compreensão do mundo, de estar no mundo e nele intervir de modo consciente e responsável.

É nesse contexto que se insere a Educação em Ciências e as discussões em torno da popularização da ciência. $\mathrm{Na}$ atualidade, ciência e a tecnologia são características marcantes nas sociedades, estão cada vez mais presentes no cotidiano das pessoas, sendo esperado que a escola possa desempenhar papel destacado no que diz respeito à promoção de uma Educação em Ciências efetiva, que assegure aos estudantes a aquisição de habilidades diversas, mobilizando conhecimentos sobre ciência e tecnologia para tomada de decisão informada em diferentes contextos.

Isso traz implicações para a ação docente, sobretudo, no que diz respeito ao Ensino de Ciências, o qual necessita romper com práticas tradicionais de ensino baseadas na memorização de conceitos técnico-científicos, para práticas mais estruturadas com questões atuais, relacionando com o contexto sócio-histórico-cultural dos indivíduos e articulado com espaços que extrapolam os limites da sala de aula e do ambiente escolar.-

Desde o final do século XIX, com o movimento internacional chamado Escola Nova (New School), nascido na Europa, que se revela uma tendência de valorização da ciência como objeto de ensino e de progresso de uma nação. Emergem novas perspectivas para o ensino e a aprendizagem de Ciências ancoradas no desenvolvimento da curiosidade, na empiria, no gosto de aprender por meio de questionamentos, de investigações, de levantamento de hipóteses e da ludicidade.

Com isso, surgem perspectivas que buscam romper com a visão de que ensino e a aprendizagem de- vem ser realizados quase que exclusivamente na e para a sala de aula. Em consequência, os espaços não formais de educação ganham cada vez mais visibilidade e valorização na medida em que possibilitam a existência de processos educacionais atrativos, interativos, desafiantes e significativos.

No contexto das políticas públicas, os espaços não formais podem se configurar como contextos em que educação formal e informal pode ocorrer e interagir. Nesse cenário, as Praças da Ciência, projeto desenvolvido pela Secretaria da Ciência, Tecnologia e Inovação da Bahia (SECTI/BA) e implantado em Municípios baianos se configura como espaço não formal de educação, abrindo possibilidades para que nesse ambiente ocorram processos educacionais diversos.

Ao considerar que a prática educativa deve ser lúdica, articulada com as questões culturais, políticas e sociais nos contextos onde ela acontece, este artigo tem por objetivo discutir as relações entre a Educação em Ciências e os espaços não formais de educação. Para isso, toma como objeto de discussão o projeto Praças da Ciência. Ainda, apresenta brevemente a trajetória da Educação em Ciências no Brasil; discute as contribuições dos espaços não formais para o ensino e a aprendizagem em Ciências; e, por fim, aponta alguns desafios e possibilidades do projeto no que concerne aos seus objetivos, abrangência e aos meios de divulgação e popularização ciência.

A produção do presente artigo se deu a partir de um levantamento bibliográfico sobre Educação em Ciências voltada para o ensino básico. O levantamento foi realizado nas plataformas de busca Scientific Electronic Library Online (SciELO), Education Resources Information Center (ERIC) e Web of Science. A busca por trabalhos considerou as palavras "Espaços Não formais" combinados com os termos "Educação em Ciências", "Ensino de Ciências", "Divulgação da Ciência", "Popularização da Ciência" e os mesmo termos correspondentes na língua inglesa. Além da revisão bibliográfica, foi realizada uma análise documental do projeto Praças da Ciência. As informações e os documentos relativos ao projeto estão disponíveis no site institucional da Secti/BA. 


\section{BREVE TRAJETÓRIA DA EDUCAÇ̃̃O EM CIÊNCIAS NO BRASIL: A ESCOLA NOVA COMO PONTO DE PARTIDA}

As mudanças sociais, econômicas e políticas ocorridas no mundo após a segunda guerra mundial impulsionaram mudanças no sistema educacional brasileiro referente às demandas de progresso da ciência e tecnologia nacionais, das quais dependia o país em processo de industrialização. Assim, foram ocorrendo mudanças na concepção do papel da escola como responsável pela educação de todos. Faz-se mister destacar que as novas demandas da sociedade ressaltam a necessidade do currículo responder aos avanços do conhecimento científico e às demandas geradas pela influência das novas correntes pedagógicas no campo educacional, dentre essas a Escola Nova, que se apresentou como caminho de renovação para a escola, buscando superar a escola tradicional.

A Escola Nova surge no final do século XIX na Europa e ganha força no Brasil nos primeiros cinquenta anos do século XX. Tinha como finalidade a superação da concepção tradicional do ensino. Assim, o aluno passa a ser o centro do processo e o professor se torna facilitador da aprendizagem, priorizando o desenvolvimento psicológico, cognitivo e a autorrealização do educando, considerado agente ativo, criativo e participativo no ensino e na aprendizagem. Os conteúdos ganham significação, são expostos por meio de atividades variadas como trabalhos em grupo, pesquisas, jogos, experiências, entre outros (SILVA, 2012). Essa tendência deslocou o eixo da questão pedagógica, valorizando a participação ativa dos estudantes nos processo pedagógicos. Destarte, as atividades práticas foram consideradas importante elemento para a compreensão de conceitos, onde se destacava o "aprender fazendo".

Nessa perspectiva, defende-se que a Educação Científica contemple tanto os produtos do fazer científico quanto os elementos necessários à compreensão das características da Ciência e do seu processo de elaboração, ou seja, da própria natureza da $\mathrm{Ci}$ ência. Segundo Moura (2014) a natureza da Ciência envolve diversos elementos relacionados à construção, estabelecimento e organização do conhecimento científico, significa saber do que a ciência é feita, como foi e é elaborada e suas bases de influências.

No contexto das políticas curriculares, no Brasil, a Lei de Diretrizes e Bases da Educação, no 4.024, de 21 de dezembro de 1961, dentre outras medidas, ampliou o estudo de Ciências no currículo (KRASILCHICK, 2000). Antes desse período, prevalecia no cenário escolar brasileiro o ensino tradicional, em que cabia aos professores a transmissão de conhecimentos acumulados pela humanidade; e, aos alunos, a absorção das informações, por meio de aulas expositivas e memorização, tornando o ato educativo incompleto e vazio.

Em meados de 1970, o cenário de crises ambientais, aumento da poluição, crise energética e efervescência social, manifestada em movimentos de estudantes, lutas raciais, determinariam transformações nas propostas das disciplinas científicas em todos os níveis de ensino (KRASILCHIK, 2000). Por conseguinte, surge a preocupação com a perspectiva histórica do conhecimento científico, suas implicações e impactos sociais com relação ao meio ambiente e ao homem. 0 ensino, então, voltou-se para a preocupação com o viver meIhor, por meio da análise das implicações científicas. Privilegiou-se, portanto, a aproximação entre Ciência e Sociedade com a inclusão da investigação científica na inter-relação dos aspectos políticos, econômicos, sociais e culturais com a finalidade de identificar problemas cotidianos e propor soluções.

Em 1996, foi promulgada a nova Lei de Diretrizes e Bases da Educação Nacional (LDBEN) no 9394/96 e, a partir dela, foram elaborados alguns importantes documentos de referência no âmbito da educação básica a exemplo dos Parâmetros Curriculares Nacionais (PCN). O conhecimento científico é tratado nos PCN como meio para o desenvolvimento da autonomia no pensar e no agir. Destarte, concebe-se a relação de ensino e aprendizagem:

[...] como uma relação entre sujeitos, em que cada um, a seu modo e com determinado papel, está envolvido 
na construção de uma compreensão dos fenômenos naturais e suas transformações, na formação de atitudes e valores humanos. [...] Dizer que o aluno é sujeito de sua aprendizagem significa afirmar que é dele o movimento de ressignificar o mundo, isto é, de construir explicações norteadas pelo conhecimento científico. (BRASIL, 1997, p. 28).

Depreende-se, portanto, que o Ensino de Ciências passa a incorporar a preocupação com a formação do cidadão crítico e participativo. As propostas educativas enfatizam a necessidade de levar os estudantes a desenvolverem o pensamento reflexivo e crítico e a se apropriarem de conhecimentos relevantes do ponto de vista científico, social e cultural.

A década de 2000 consolida as discussões no campo da Educação em Ciências, enfatizando a necessidade de responsabilidade social e ambiental por parte de todos os cidadãos. Enfatiza-se a existência de amplas relações entre a Ciência, a Tecnologia, a Sociedade e o Meio Ambiente, além da promoção da formação de cidadãos capazes de fazer opções de modo consciente.

Busca-se, portanto, dar ênfase à formação de cidadãos capazes de fazer opções de modo consciente, bem como a existência de amplas relações entre a Ciência, a Tecnologia, a Sociedade e o Meio Ambiente, o qual ficou conhecido como movimento CTSA. A Educação CTSA busca inserir no Ensino de Ciências discussões e correlações existentes entre Ciência Tecnologia - Sociedade - Ambiente, a fim de que, por meio da alfabetização científica, os estudantes sejam capazes de compreender essas interações, tornando-se cidadãos informados, críticos e ativos na sociedade em que vivem.

Ainda em relação aos documentos oficiais, cumpre-se registrar que o Ministério da Educação homologou recentemente, em dezembro de 2017, a Base Nacional Comum Curricular (BNCC), com o objetivo de organizar e determinar o conteúdo mínimo que deve ser objeto de ensino em todas as escolas de educação básica públicas e privadas do país. No entanto, esta versão abarca apenas a educação infantil e o ensino fundamental. A versão para o ensino mé- dio está em fase de apreciação pelo Conselho Nacional de Educação.

De acordo com a versão final da BNCC referente ao ensino fundamental,

\begin{abstract}
A área de Ciências da Natureza tem compromisso com o desenvolvimento do letramento científico, que envolve a capacidade de compreender e interpretar o mundo (natural, social e tecnológico) e também de transformá-lo com base nos aportes teóricos e processuais das ciências. (BRASIL, 2017, p. 320).
\end{abstract}

Ainda, segundo os textos da base, o letramento científico não é a última finalidade da aprendizagem em Ciências, mas o desenvolvimento de capacidades de atuar no mundo e sobre o mundo. Nesse sentido, a Educação Científica precisa assegurar aos estudantes o acesso à diversidade dos conhecimentos científicos que foram produzidos historicamente e seus processos e práticas investigativas. Assim, há sugestões de promover situações problemas e vivências diversas para que, ancorados nos conhecimentos científicos, os estudantes possam ser capazes de posicionar-se no mundo em que vivem, e fazer escolhas e intervenções diante de problemas vivenciados.

Vieira e outros autores (2017) ressaltam que aprender ciência corresponde, principalmente, em empoderar intelectualmente com recursos científicos da época, considerando os contextos históricos e culturais. Desse modo, os espaços não formais de educação que se processam por meio de instrumentos variados como centros de Ciências, museus, praças, observatórios, entre outros, têm adquirido importância crescente, revelando-se instrumentos com forte potencial na formação da cultura científica de diversos sujeitos.

\section{CONTRIBUIÇ̃̃ES DOS ESPAÇOS NÃO-FORMAIS PARA O ENSINO E A APRENDIZAGEM EM CIÊNCIAS}

O ensino e a aprendizagem de Ciências pode se processar em diversos contextos e espaços. Diferentes definições, nem sempre consensuais, têm sido apontadas ao se discutir os distintos espaços em que 
se situam os processos educacionais (JACOUBUCCI, 2008; OLIVEIRA; GASTAL, 2009).

O termo "espaço não formal” tem sido utilizado genericamente, por pesquisadores em educação e professores de diversas áreas do conhecimento para descrever lugares, diferentes do espaço escolar, onde é possível desenvolver atividades educativas. No entanto, para Jacobucci (2008), duas categorias podem ser sugeridas para uma definição mais precisa de espaços não formais: locais que são instituições e locais que não são instituições. Enquanto que a categoria instituições abrange os espaços que são regulamentados e que possuem equipe técnica responsável pelas atividades executadas, a categoria não institucional engloba os ambientes naturais ou urbanos que não dispõem de estruturação institucional, mas é possível adotar práticas educativas.

Por sua vez, Gadotti (2005) define a educação não formal, considerando sua especificidade, que é a característica de ser difusa, menos hierárquica e menos burocrática. 0 autor considera ainda que toda educação é intencional e, nesse sentido, a educação não formal se diferencia da formal não pela oposição, mas por realizar-se fora do sistema formal. A educação não formal se realiza em espaços e tempos distintos da educação formal. Para uma maior compreensão sobre esses conceitos, tomou-se como referência, neste trabalho, que os espaços formais de educação referem-se a instituições educacionais, enquanto que os espaços não formais relacionam-se com ambientes cuja função básica não é a educação formal.

Percebe-se que há uma distinção em relação ao espaço onde acontece o processo educacional e o tipo de educação realizada, podendo elucidar distinções existente entre educação formal, informal e não formal e espaços formais e não formais onde se processa a educação. Os espaços não formais de educação podem ser considerados os ambientes fora do espaço geográfico da escola. Pode se constituir em um espaço não formal uma fábrica, museu, zoológico, feiras, parques, praças, entre tantos outros possíveis.

Oliveira e Gatsal (2009) apontam outros elementos nessa distinção, tais como os sujeitos envolvidos, a existência de intencionalidade didática, a utilização de metodologias, técnicas e equipamentos específicas, procedimentos didáticos e processos avaliativos. Alguns espaços não formais de educação têm se constituído campo fértil para pesquisas que buscam compreender, principalmente, as suas relações com a educação formal, com as aprendizagens e com as contribuições em relação à divulgação e popularização da ciência.

Germano e Kulesza (2007, p. 14) destacam que enquanto a divulgação científica é "a veiculação em termos simples da ciência como processo, dos princípios nela estabelecidos, das metodologias que emprega [...]" a popularização é "o ato ou ação de popularizar, tornar popular, difundir algo entre o povo" (GERMANO; KULESZA, 2007 p. 19). Embora haja distinções, os conceitos aparentam possuir matrizes de um mesmo princípio, que é promover o diálogo entre o conhecimento científico e o cotidiano das pessoas.

Os espaços não formais de educação possuem grande potencial de contribuição na divulgação e popularização da investigação e da tecnologia, contribuindo para a educação formal, informal e não formal, instaurando-se como meio de um diálogo entre Ciência e a sociedade como um todo. De fato, esses espaços têm assumido cada vez mais importância no âmbito do Ensino de Ciências e das modalidades pedagógicas que têm por finalidade um processo de aprendizagem cada vez mais investigativo, interativo e significante.

A aprendizagem significativa aqui é entendida de acordo com a visão clássica de David Ausubel (1963), que é processo por meio do qual uma nova informação, um novo conhecimento, relaciona-se de maneira não arbitrária e substantiva à estrutura cognitiva do aprendiz. Para Moreira (2012), é no curso da aprendizagem significativa que o significado lógico do material de aprendizagem se transforma em significado psicológico para o sujeito. Daí os educandos buscam entender o significado do que estudam, estabelecendo relações com os conhecimentos adquiridos anteriormente, empenhando-se para compreender e interagir com os mesmos. Por outro lado, quando o material de aprendizagem é relacionável à estrutura cognitiva somente de ma- 
neira arbitrária e literal, que não resulta na aquisição de significados para o sujeito, a aprendizagem é dita mecânica ou automática.

Nessa perspectiva, percebe-se intrínseca relação entre aprendizagem significativa e interação social, já que é no curso da aprendizagem significativa, permeado de intercâmbio, troca de significados que o significado lógico dos materiais de aprendizagem se transforma em significado psicológico para o aprendiz. Portanto, a aprendizagem significativa depende de interação social, objeto de estudo de Vygotsky (1988), ou seja, a aquisição de significados e a interação social são inseparáveis, visto que os significados são construídos socialmente. Destarte, o desenvolvimento cognitivo não pode ser entendido sem referência ao contexto em que ocorre.

Os estudos de Vygotsky (1988) enfatizam o papel da aprendizagem no desenvolvimento humano, valorizando o papel da interação social. Numa descrição simplificada, pode-se compreender que, nessas interações, em relação a um determinado conhecimento a ser partilhado, nossa mente cria as estruturas cognitivas necessárias à compreensão de um determinado conceito à medida que esse conceito for ensinado, ou melhor, à medida que esse conceito está sendo aprendido (NEVES; DAMIANI, 2006). Depreende-se que esse processo se faz presente no contexto dos espaços não formais de educação desde que os conhecimentos sejam compartilhados em meio a uma interação sociocultural que tem, como condição necessária e suficiente, existir quem saiba e quem queira saber.

Portanto, as razões acima elencadas se contrapõem ao ensino memorístico, acrítico e a-histórico, praticado na maioria dos espaços formais de educação, onde a curiosidade e criatividade muitas vezes não são valorizadas. Educação em Ciências é uma prática social que vem sendo cada vez mais ampliada e fortalecida em espaços não formais de educação. Deste modo, torna-se relevante o desenvolvimento de políticas públicas e estratégias pedagógicas que auxiliem na compreensão do conhecimento científico, por meio de experiências, também, fora do espaço escolar.

\section{PROJETO PRAÇAS DA CIÊNCIAS NOESTADO DA BAHIA}

O projeto Praças da Ciência surgiu em 2014, trata-se de uma iniciativa do Governo do Estado da Bahia, formulado por intermédio da Secti/BA. O objetivo declarado do projeto é o de popularizar a Ciência nos espaços públicos, despertando nas pessoas o interesse por conhecimentos em tecnologia e inovação (BAHIA, 2014). Em se tratando da abrangência do projeto, a meta é implantar as praças em quarenta Municípios baianos, por meio da instalação de oito equipamentos educativos: conchas, bicicleta geradora, harpa, alavanca, gangorra de comprimentos diferentes, cadeira giratória, balanços de comprimentos diferentes e basquete giratório, como ilustrado na Figura 1.

Figura 1 - Equipamentos educativos implantados no projeto Praças da Ciência

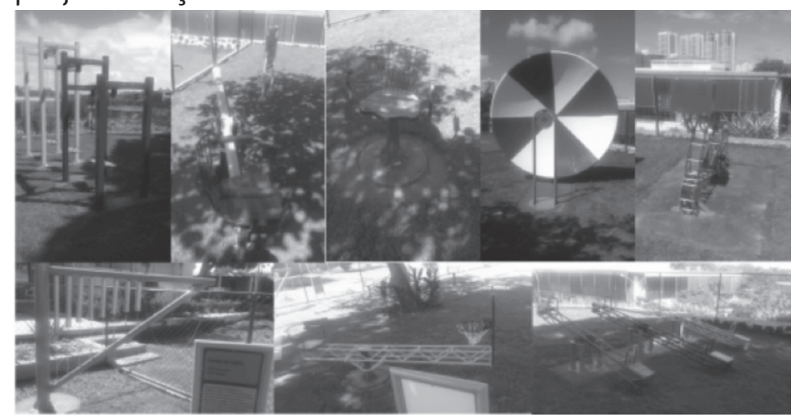

Fonte: BAHIA (2014)

O objetivo principal do projeto é de promover e incentivar o conhecimento científico de maneira lúdica e interativa e que colabore no processo de ensino e de aprendizagem da Ciência. Sendo assim, espera-se que nesse espaço não formal ocorra, também, a educação formal.

Até fevereiro de 2018, vinte e sete Praças de Ciência foram implantadas em Municípios baianos. Não há evidências de como ocorrem a seleção e o atendimento aos Municípios para o recebimento dos equipamentos. Indica-se, somente, que as praças são 
implantadas mediante convênio com as prefeituras municipais interessadas em adquiri-la, sendo que o Município cede o espaço e o Estado da Bahia, através da Secti/BA, disponibiliza os equipamentos, inclusive a montagem (BAHIA, 2014).

A meta de atendimento do projeto - quarenta municípios - tomando-se como parâmetro o número de Municípios baianos, quatrocentos e dezessete, é limitada, abrangendo, somente $10 \%$ dos Municípios, aproximadamente. Além disso, os dados disponíveis não mencionam prazos para atendimento, nem informações sobre as possibilidades de articulação entre as praças e as secretarias municipais de educação. Apreende-se que a popularização da Ciência já entrou na agenda governamental, porém não na dimensão necessária de centralidade política e investimentos que permitam cumprir a importante missão social que é capaz de realizar por meio dessa proposta.

Os espaços não formais de educação, neste caso as Praças da Ciência, não se constituem em institutos de pesquisa científica, stricto sensu; desse modo, seu potencial está condicionado a questões pedagógicas ligadas à divulgação e popularização dos saberes neles veiculados. Conforme assinalado neste trabalho, sua finalidade adquire sentido à medida que ações pedagógicas intencionais e planejadas direcionam uma reflexão sistêmica da relação ser humano e natureza, fazendo com que o estudante se dê conta das inúmeras possibilidades que esta experiência proporciona para sua aprendizagem, relacionando aspectos conceituais com atividades lúdicas, tornando-a significativa no sentido posto por Moreira (2012) de ampliar e reconfigurar ideias e, com isso, ser capaz de relacionar e acessar novos conhecimentos.

Na formulação do projeto Praças da Ciência não houve uma articulação com a Secretaria da Educação do Estado da Bahia (SEC/BA), dessa maneira, inúmeras possibilidades estruturais e pedagógicas poderiam ter sido articuladas, resultando em um melhor aproveitamento das praças. No entanto, em se tratando da questão de articulação entre as duas Secretarias de Estado, no desenvolvimento do projeto merece destaque o documento “Práticas para
Compartilhar: Praças da Ciência”, elaborado por professores vinculados à SEC/BA e destinado aos estudantes, professores e público em geral.

O material didático descreve cada equipamento que compõe a Praça a partir de sua composição, formas de utilização, conceitos imbricados e aplicações no cotidiano. Além disso, apresenta links que remetem ao aprofundamento dos conhecimentos e questões desafiadoras, envolvendo os conceitos científicos ligados principalmente à Física.

0 projeto Praças de Ciências é importante por diversos aspectos, um deles põe em evidência a necessidade de aproximar cada vez mais o desenvolvimento científico e tecnológico com o cotidiano das pessoas, buscando concretizar a popularização da ciência. Procura contribuir com a educação formal no processo de aquisição e apreensão dos conhecimentos técnicos e científicos e ao mesmo tempo considera que a formação do indivíduo não se restringe aos espaços formais, como o escolar.

Diante das dificuldades de acesso à educação científica, bem como às informações relevantes sobre ciência e tecnologia, a iniciativa do projeto Praças da Ciência pode contribuir com a Educação em Ciências desde a primeira etapa da educação básica - educação infantil - ao ensino superior, assim como estimular o diálogo, discussões, curiosidades e interesse pela Ciência em qualquer indivíduo, estando ou não inserido em uma instituição educacional ou em processos formais de educação. Todavia, presume-se que seus objetivos se tornarão exequíveis a partir da definição e execução de estratégias robustas e regulares no campo da divulgação e popularização de conhecimentos científicos e tecnológicos em articulação com a escola e sociedade civil.

Dessa forma, interessa ampliar os espaços de formação complementar, que efetivamente possam contribuir com a cultura científica, despertando o interesse pela Ciência e ampliando o conhecimento e sua importância no cotidiano da vida social. Essa proposta pode ser melhor (re)formulada, ampliada e articulada com as secretarias de educação dos municípios, a fim de propiciar situações viáveis e sustentáveis para o 
seu maior aproveitamento. Deve, portanto, se constituir como política pública e não como mera ação pontual de governo, pois, evidencia-se, uma oportunidade de dispor e utilizar um ambiente de aprendizagem em que o público possa ter um papel ativo na construção dos seus conhecimentos, possibilitando a apropriação e contextualização de conhecimentos científicos e tecnológicos por meio do entretenimento.

Outras iniciativas relacionadas à divulgação e popularização dos saberes articulados ao projeto Praças da Ciência em articulação com a escola podem ser apresentadas com a finalidade de explorar as relações entre espaços formais e espaços não formais de educação, possibilitando a articulação permanente entre as experiências de ensino e aprendizagem. Neste âmbito, não podem ser ignoradas as possíveis contribuições das universidades e instituições públicas de pesquisa, diante do inquestionável potencial de produção de conhecimento científico.

\section{CONSIDERACÕES FINAIS}

É indiscutível o importante papel dos espaços não formais, a exemplo do projeto Praças da Ciência implantado pelo Estado da Bahia, como espaços que aproximam a sociedade do conhecimento científico, constituindo-se em ambientes enriquecedores e de motivação para a formação de estudantes e da comunidade em geral no âmbito da educação em $\mathrm{Ci}$ ências. Todavia, a finalidade desses espaços pode ser potencializada a partir de maior articulação com outras instituições e atores sociais, por exemplo, as secretarias de governos, as escolas e a sociedade civil, representando um ponto de ancoragem e por meio dele possam ser divulgados e popularizados conhecimentos científicos necessários ao desenvolvimento de múltiplas aprendizagens, não só de estudantes, mas da população em geral.

As potencialidades que os diferentes espaços além das escolas exercem na aquisição de conhecimentos, em especial, os conhecimentos científicos, precisam ser evidenciadas além de apontadas as estratégias viáveis para construção e utilização desses ambientes. As discussões apresentadas dão conta de que os espaços não formais de educação cumprem sua maior função como potencial instrumento formativo na medida em que ações pedagógicas planejadas direcionam uma reflexão sistêmica da relação Ciência-Tecnologia-Sociedade- Ambiente. Desse modo, tornam-se necessárias estratégias que aproximem a sociedade dos saberes veiculados ao projeto Praças da Ciência.

Nesse sentido, admite-se que há interesse do Estado da Bahia em prover mecanismos de aproximar os conhecimentos cientificamente sistematizados com a população em âmbito geral por meio de espaços não formais. Não obstante, o projeto Praças da Ciência, foco de análise deste trabalho, carece de maior abrangência e articulação com outros órgãos, ratificando a importância de maiores investimentos, tendo em vista a relevância que esses espaços desempenham para a Educação em Ciências, seja em âmbito da educação formal ou não.

\section{REFERÊNCIAS}

\section{AUSUBEL, D. P. The psychology of meaningful}

verbal learning. New York: Grune and Stratton, 1963.

BAHIA, Secretaria de Ciência, Tecnologia e Informação. Praças da Ciência. 2014. Disponível em: http://www.secti.ba.gov.br/modules /conteudo. php?conteudo=33. Acesso em: 5 mar. 2018.

BAHIA, Secretaria da Educação. Secretaria de Ciência, Tecnologia e Informação. Práticas para

Compartilhar: Praças da Ciência - Estudantes. 2016. Disponível em: http://www.secti.ba.gov.br/arquivos/ File/EDITAIS/praca.pdf. Acesso em: 21 jun. 2018.

BRASIL. Ministério da Educação. Base Nacional

Comum Curricular. Versão final. Brasília, 2017. Disponível em: http://basenacionalcomum.mec.gov. br/. Acesso em: 10 mar. 2018. 
BRASIL. Secretaria de Educação Fundamental. Parâmetros Curriculares Nacionais: Ciências Naturais. Brasília, 1997. Disponível em: http://portal. mec.gov.br/seb/arquivos/pdf/ciencias.pdf.

Acesso em: 10 mar. 2018.

\section{GADOTTI, Moacir. A questão da educação formal/} não-formal. Droit à l'education: solution à tous les problèmes sans solution? Institut International des droits de l'enfant, Sion, 2005.

GERMANO, M. G.; KULESZA, W. A. D. Popularização da Ciência: uma revisão conceitual. Caderno Brasileiro de Ensino de Física, v. 24, n. 1, p. 7-25, 2007.

JACOBUCCI, D. F. C. Contribuições dos espaços não-formais de educação para a formação da cultura científica. Em extensão: Uberlândia, v. 7, 2008.

\section{MOREIRA, M. A. 0 que é afinal aprendizagem}

significativa? 2012. Porto Alegre: Instituto de Física da UFRGS. Disponível em: http://www.if.ufrgs. br/ moreira/alfinal.pdf. Acesso em: 2 mar. 2018.

MOURA, B. A. O que é natureza da ciência e qual sua relação com a História e Filosofia da Ciência? Revista Brasileira de História da Ciência, v. 7, n. 1, p. 32-46, 2014.

OLIVEIRA, R. I. R.; GASTAL, M. L. A. Educação formal fora da sala de aula - olhares sobre o ensino de ciências utilizando espaços não formais. Encontro Nacional de Pesquisa em Educação em Ciências, 9 VII ENPEC, Anais [...], Florianópolis, 2009.

KRASILCHIK, M. Reformas e realidade: o caso do ensino de ciências. São Paulo em perspectiva, n. 14, v. 1, p. 85-93, 2000.

MOREIRA, I. A inclusão social e a popularização da ciência e tecnologia no Brasil. Revista Inclusão Social, v. 1, n. 2, p. 11-16, 2006.

NEVES, M. F.; DAMIANI, R. A. Vygotsky e as teorias da aprendizagem. UNIrevista, São Leopoldo, v. 1, n. 2, p.1-10, 2006.

SILVA, A. P. $O$ embate entre a Pedagogia Tradicional e a Educação Nova: Políticas e Práticas Educacionais na Escola Primária Catarinense (1911-1945). Anped Sul, 9, 2012, Caxias do Sul. Anais [...], Caxias do Sul: UCS, 2012, p. 1-16.

VIEIRA, R. D.; MELO, V. F.; AVRAAMIDOU, L.; LOBATO, J. A. Reconceptualizing Scientific Literacy: The Role of Students' Epistemological Profiles.

Education Sciences Journal. 2017, p.7-47, disponível em: www.mdpi.com/journal/education. Acesso em: 21 jun. 2018.

VYGOTSKY, L. S. A formação social da mente. 2. ed. Brasileira, São Paulo: Martins Fontes, 1988. 
1 Doutorado em Educação pela Universidade Federal da Bahia UFBA; Mestrado em Educação - UFBA; Graduado em Pedagogia pela Universidade do Estado da Bahia - UNEB; Especialista em Política do Planejamento Pedagógico: currículo, didática e avaliação - UNEB; Pesquisador do Grupo de Pesquisa Política e Gestão da Educação da UFBA e do Grupo de Pesquisa Gestão e Avaliação de Politicas e Projetos Sociais - GAPPS, da Universidade Católica do Salvador UCSal; Parecerista ad- hoc da Revista Roteiro (ISSN 0104-4311) do Programa de Pós-Graduação em Educação da Universidade do Oeste de Santa Catarina - UNOESC; Tem experiência na área de Educação, com ênfase em Gestão, atuando principalmente nos seguintes temas: Políticas Públicas, Formação de Professores, Atuação do Coordenador Pedagógico, Práticas Pedagógicas, Financiamento da Educação e Organização de Sistemas de Ensino. E-mail: eanmario.pce@gmail.com

2 Mestre em Saúde Comunitária pelo Instituto de Saúde Coletiva - ISC/ UFBA; Especialista em Gestão em Saúde pela Universidade Aberta do Brasil/ Escola Nacional de Saúde Pública - ENSP/FIOCRUZ; Graduada em Odontologia e em Ciências Naturais, Universidade Federal da Bahia - UFBA; Doutoranda em Ensino, Filosofia e História das Ciências pela Universidade Federal da Bahia; Atuou na Docência da Educação Básica pela Secretaria da Educação do Estado da Bahia e na Gestão da Atenção Básica da Saúde pela Secretaria da Saúde do Estado da Bahia; Tem experiência na área da educação e da saúde, atuando em pesquisas, principalmente, nos seguintes temas: Saúde Bucal, Ensino e Educação em Saúde, Infância e Saúde e Saúde na Escola. E-mail: mcaires7@gmail.com

3 Doutora (1982) e pós-doutora (1986) em Administração da educação Educational Administration - The Pennsylvania State University; Mestre em Curriculum e Instrução - The Pennsylvania State University (1979); Graduada em Letras (1968) e Pedagogia pela Universidade Federal da Bahia - UFBA (1975); Professora pesquisadora da Universidade Católica de Salvador - UCSAL, Programa de Políticas Sociais e Cidadania; Experiência na área de Educação, com ênfase em Administração Educacional, atuando nos temas: gestão e avaliação de políticas sociais, administração e gestão de escolas públicas, administração e gestão da educação, gestão e avaliação da educação presencial e a distância, educação de adultos; Foi Editora da revista Gestão em Ação, VicePresidente Nacional da Associação Nacional de Política e Administração da Educação (ANPAE- bienio 2000-2002) e Vice- Presidente da Região Nordeste da ANPAE (bienio2006-2007); Membro do corpo editorial de revistas científicas; Foi Vice-coordenadora da Câmara de Assessoramento e Avaliação Técnico -Científico da FAPESB - área EDUCAÇÃO - período dezembro/2006 a dezembro/2008; Vice-coordenadora da Câmara de Ciências Humanas e Educação no período 2009-2010; Lider do grupo de pesquisa GAPPS e vice líder do grupo Políticas Públicas e Gestão Escolar: Tem experiência internacional em vários países como: a) Timor Leste onde lecionou gestão da educação na Universidade do Timor Leste - LAROSA? em Dilli, capital do pais, como parte de um projeto interinstitucional conjunto com a UFBA , b) Venezuela? na Universidade Nacional Aberta da Venezuela- realizou a pesquisa para tese de doutorado, c) nos Estados Unidos além de realizar seus estudos de mestrado, doutorado e pós-doutorado na The Pennsylvania State University, fez palestras na Universidade de Stanford em Palo Alto, California, esteve em contato com pesquisadores da Universidade da Califórnia, outras, d) em 2017, fez várias visitas técnicas a quatro Universidades no exterior, foram elas - à universidade Jawaharlal Nehru, ( Jawaharlal Nehru University) em nova Delli , India, assim como a Universidade de Johanesburgo na Africa do Sul(University of Johannesburg ? South Africa) e também as Universidade do Minho e de Coimbra, as duas últimas em Portugal. 
